\title{
Utilização de aditivos em rações formuladas com milho normal e de baixa qualidade para frangos de corte ${ }^{1}$
}

\author{
Mauro Jarbas de Souza Godoi ${ }^{2}$, Luiz Fernando Teixeira Albino ${ }^{3}$, Horacio Santiago Rostagno ${ }^{3}$, \\ Paulo Cezar Gomes ${ }^{3}$, Sergio Luiz de Toledo Barreto ${ }^{3}$, José Geraldo de Vargas Junior ${ }^{4}$
}

\author{
1 Projeto financiado pele Biorigim. \\ 2 Programa de Pós-graduação em Zootecnia - UFV, Viçosa - MG. \\ ${ }^{3}$ DZO/UFV, Campus Universitário - Viçosa - MG.
}

${ }^{4}$ DZO/CCA/UFES, Alegre - ES.

RESUMO - Foi conduzido um experimento com 2.112 pintos de corte, machos da linhagem Ross, para avaliar a influência da utilização de aditivos não-nutrientes (antibiótico, prebiótico e simbiótico) sobre o desempenho e as características de carcaça de frangos de corte. As aves foram distribuídas em delineamento inteiramente casualizado, em arranjo fatorial $2 \times 6$ (milho $\times$ aditivo), totalizando 12 tratamentos, com oito repetições e 22 aves por unidade experimental. As rações foram formuladas à base de milho e farelo de soja, utilizando-se, na metade dos tratamentos, milho de qualidade normal $\left(\mathrm{T}_{1}, \mathrm{~T}_{2}, \mathrm{~T}_{3}, \mathrm{~T}_{4}, \mathrm{~T}_{5} \mathrm{e}\right.$ $\mathrm{T}_{6}$ ) e na outra metade, milho de baixa qualidade $\left(\mathrm{T}_{7}, \mathrm{~T}_{8}, \mathrm{~T}_{9}, \mathrm{~T}_{10}, \mathrm{~T}_{11}\right.$ e $\left.\mathrm{T}_{12}\right)$. Os tratamentos foram: $\mathrm{T}_{1}$ e $\mathrm{T}_{7}=$ ração basal $(\mathrm{RB}) ; \mathrm{T}_{2}$ e $\mathrm{T} 8=\mathrm{RB}+$ antibiótico; $\mathrm{T}_{3}$ e $\mathrm{T}_{9}=\mathrm{RB}+$ simbiótico; $\mathrm{T}_{4}$ e $\mathrm{T}_{10}=\mathrm{RB}+$ prebiótico $1(0,5 \mathrm{~kg} / \mathrm{t}) ; \mathrm{T}_{5}$ e $\mathrm{T}_{11}=\mathrm{RB}+$ prebiótico $1(1,0 \mathrm{~kg} / \mathrm{t}) ;$ e $\mathrm{T}_{6}$ e $\mathrm{T}_{12}=\mathrm{RB}+$ prebiótico $2(1,0 \mathrm{~kg} / \mathrm{t})$. Para aumentar o desafio sanitário, além da cama reutilizada, os bebedouros não foram lavados periodicamente, com o objetivo de piorar a qualidade da água de bebida. Aos 21 e 42 dias de idade, foram avaliados ganho de peso, consumo de ração e conversão alimentar. Aos 23 dias de idade, foram avaliadas as características físicas do fígado e a presença de petéquias no peito e na coxa e aos 42 dias, as características de carcaça e o peso relativo do fígado. Verificou-se efeito do aditivo somente para ganho de peso aos 21 dias e para ganho de peso e consumo de ração aos 42 dias. Não foi observado efeito dos aditivos sobre as demais características avaliadas. Os prebióticos à base de mananoligossacarídeos e o simbiótico podem substituir o antibiótico avilamicina nas rações para aves, pois não promoveram perdas no desempenho das aves. O uso de milho de baixa qualidade piorou o desempenho, provocando perdas no rendimento e na qualidade de carcaça de frangos de corte.

Palavras-chave: antibiótico, carcaça, desempenho, fígado, mananoligossacarídeos, simbiótico

\section{Additive in diets formulated with standard and low quality corn for broiler chickens}

\begin{abstract}
An experiment was conducted with 2,112 Ross male broiler chicks, with the objective to evaluate the use of non-nutrient additives (antibiotic, prebiotic and symbiotic) on performance and carcass characteristics of broilers. The birds were distributed in a complete randomized design in $2 \times 6$ (corn $\times$ additive) factorial arrangement, with 12 rations, eight replicates and 22 birds per experimental unit. Diets were based on corn and soybean meal, using in the half the rations standard quality corn (Rations 1 to 6 ) and the other half low quality corn (Rations 7 to 12). The rations were: 1 and 7, basal diet (BD); 2 and 8, BD + antibiotic; 3 and 9, BD + Symbiotic; 4 and 10, BD + prebiotic $1(0.5 \mathrm{~kg} / \mathrm{t}) ; 5$ and 11, BD + prebiotic 1 (1.0 kg/t) and 6 and $12 \mathrm{BD}+$ prebiotic $2(1.0 \mathrm{~kg} / \mathrm{t})$. To increase the animal health challenge, beyond the reused bed, drinkers were not periodically cleaned, with the objective to decrease water quality. Average weight gain, feed intake and feed conversion ratio were evaluated at 21 and 42 days of age. At 23 days of age, the physical characteristic of liver and the presence of petechias in the breast and drumstick were determined, and at 42 days of age, the carcass characteristics and relative liver weight were also evaluated. Additive effect on average weight gain at 21days age, and on average weight gain and feed intake at 42 days age was observed. There was no additive effect on the others evaluated characteristics. The prebiotic based on mannanoligosaccharides and symbiotic can replace antibiotic avilamicin in broiler diets, therefore they had not promoted losses in the performance of the birds. The uses of low quality corn worse the animal performance, with decresaing yield and carcass quality of broiler chickens.
\end{abstract}

Key Words: antibiotic, carcass, liver, mannanoligosaccharides, performance, symbiotic 


\section{Introdução}

Os avanços alcançados na avicultura são reflexos de programas de melhoramento genético que têm promovido melhorias na produção de carne e ovos e de sistemas de alimentação com o aprimoramento das exigências nutricionais. Além disso, utilizam-se aditivos promotores de crescimento e ingredientes de alta qualidade, com disponibilidade de nutrientes conhecida.

Os aditivos são utilizados na produção animal com os objetivos de aumentar as taxas de crescimento e sobrevivência, melhorar a saúde do trato gastrintestinal e a eficiência alimentar, poupar energia e reduzir as cargas patogênicas e a produção de dejetos, minimizando o impacto ambiental pela redução da transmissão de patógenos via alimentos. Esses aditivos representam aproximadamente 0,08\% em volume e 2,60\% do custo da ração, que é alto se comparado ao do milho, que representa $65,5 \%$ do volume e $38,0 \%$ do custo da ração (Silva, 2004). Entre os diversos aditivos nãonutrientes utilizados em rações para aves, destacam-se os antibióticos, os prebióticos, os probióticos, os simbióticos, os ácidos orgânicos e os fitoterápicos.

Os antibióticos são utilizados como promotores de crescimento em rações animais desde a década de 50 (Araujo et al., 2000). No entanto, o uso constante tem preocupado a comunidade científica, em razão da possibilidade de deixar resíduos na carne, proporcionando resistência aos microrganismos e prejudicando a saúde humana.

No Brasil, a grande preocupação das empresas exportadoras é que, desde janeiro de 2006, existem restrições ao uso de antibióticos nas rações. Portanto, são necessárias alternativas - prebióticos, probióticos e simbióticos para manutenção dos índices de produção alcançados. Os prebióticos mais estudados como aditivos na alimentação animal são os oligossacarídeos, especialmente os mananoligossacarídeos (MOS), os frutoligossacarídeos (FOS) e os glucoligossacarídeos (GOS).

Mananoligossacarideos têm como função melhorar e proteger a mucosa, reduzindo as lesões intestinais e propiciando maior altura dos vilos e da profundidade de cripta, (Luquetti et al., 2005; Pelicano et al., 2005), melhorando a digestibilidade e o teor da energia metabolizável das rações, pois propicia o desenvolvimento da flora intestinal (Albino et al., 2006).

Os mananoligossacarídeos podem ser utilizados como adsorventes de aflatoxinas, pois reduzem os problemas causados pelas micotoxinas, normalmente presentes no milho de baixa qualidade (Stringhini et al., 2000).

Simbiótico é o termo utilizado para designar a associação de prebiótico e probiótico em um só produto. Desta forma, componentes da microbiota intestinal e substâncias prebióticas específicas podem ser fornecidos em conjunto, pois podem estimular o desenvolvimento e a atividade desta mesma microbiota, permitindo potencializar o efeito de ambos os componentes, e ser utilizados em criação de frangos de corte em substituição ao antibiótico, pois não altera o rendimento de carcaça e a ocorrência de lesões no intestino das aves (Pelícia et al., 2004).

O milho também assume fundamental importância na alimentação, visto que compõe cerca de $60 \%$ da ração inicial de frangos de corte, o que corresponde a aproximadamente $65 \%$ da energia metabolizável e $22 \%$ da proteína na fase inicial.

Para efeito de avaliação de sua qualidade, no Brasil, o milho é classificado como tipos 1, 2 e 3, conforme o grau de impurezas e a proporção de grãos quebrados, chochos ou mofados. O milho tipo 1 é aquele que contém $1 \%$ de matérias estranhas, impurezas e fragmentos e até $11 \%$ de milho avariados; o tipo 2, até $2 \%$ de matérias estranhas, impureza e fragmentos e até $18 \%$ de milhos avariados; e o tipo 3, até $3 \%$ de matérias estranhas, impurezas e fragmentos e até $24 \%$ de milhos avariados (Tardin,1991). Tem-se observado que, nas fábricas de ração, muitas vezes, encontram-se disponíveis apenas grãos de qualidade ruim ou duvidosa, como o tipo 3, devendo-se proceder à correção nutricional da ração, o que, em muitos casos, não é feito.

Objetivou-se com este trabalho avaliar os efeitos da adição de prebiótico (à base de mananoligossacarídeos), simbiótico (à base de Bacillus subitilis + Bacillus licheniformis) e do antibiótico avilamicina, em dietas formuladas com milho normal e de baixa qualidade, sobre o desempenho, as características morfológicas dos órgãos e o rendimento de carcaça de frangos de corte.

\section{Material e Métodos}

O experimento foi conduzido no setor de Avicultura do Departamento de Zootecnia da Universidade Federal de Viçosa, no período de julho a agosto de 2004.

Utilizaram-se 2.112 pintos de corte machos, da linhagen Ross de um dia de idade, alojados em galpão experimental dividido em boxes $(1,0 \times 2,0 \mathrm{~m})$, forrados com cama reutilizada. No início do experimento, os pintos foram pesados (peso médio de $42 \mathrm{~g}$ ) e distribuídos em grupos de 22 por boxe, onde foram criados até 42 dias de idade.

O delineamento experimental utilizado foi o inteiramente casualizado, em arranjo fatorial $2 \times 6$ (milho $\times$ aditivo), com oito repetições por tratamento, totalizando 96 unidades experimentais. As dietas foram compostas por dois tipos de milho, um normal $\left(\mathrm{T}_{1}\right.$ a $\left.\mathrm{T}_{6}\right)$ e outro de baixa qualidade 
$\left(\mathrm{T}_{7}\right.$ a $\left.\mathrm{T}_{12}\right)$ (Tabela 1 ), e suplementadas ou não com aditivos não-nutrientes (avilamicina, prebióticos à base de mananoligossacarídeos - MOS e simbiótico). O milho normal foi classificado como tipo 1, enquanto o milho de baixa qualidade estava abaixo dos padrões de classificação. O milho de baixa qualidade foi retirado das paredes e dos fundos de silos, compostos, em grande parte, por grãos podres, ardidos e mofados. As amostras dos milhos e das rações que utilizaram milho de baixa qualidade foram enviadas para o Laboratório de Controle de Qualidade e Segurança Alimentar do Ministério da Agricultura Pecuária e Abastecimento - Delegacia Federal de Agricultura/DFAMG no/LAQSA, em Belo Horizonte-MG, para análise dos níveis de aflatoxinas. Os resultados das análises de aflatoxinas foram: milho normal, 0,0 ppb; milho de baixa qualidade, 137,2 ppb; ração inicial com milho de baixa qualidade, 62,8 ppb; ração final com milho de baixa qualidade, 88,1 ppb. Esses níveis de aflatoxinas estão acima dos 20 ppb (MAPA, 1998) aceitáveis em alimentos para animais. Em análises prévias, o milho normal (Tabela 2) apresentou 0,0 ppb e, portanto, não foi realizada análise de aflatoxinas nas rações em que se utilizou este milho.

As dietas (Tabela 3) fornecidas às aves nos períodos de 1 a 21 dias e de 22 a 42 dias de idade foram à base de milho e farelo de soja, formuladas de acordo com as exigências nutricionais (Rostagno et al., 2000). Para obtenção dos tratamentos, os aditivos foram adicionados em substituição ao amido da ração basal e o milho normal foi substituído

Tabela 1 - Tratamentos utilizados no período de 1 a 42 dias de idade

\begin{tabular}{cc}
\hline Milho normal & Milho de baixa qualidade \\
\hline \multicolumn{2}{c}{ Tratamento } \\
T1 - Ração basal (RB) & T7 - Ração basal (RB) \\
T2 - RB + antibiótico 1 & T8 - RB + antibiótico 1 \\
T3 - RB + simbiótico 2 & T9 - RB + simbiótico 2 \\
T4 - RB + MOS $1^{3}-0,5 \mathrm{~kg} / \mathrm{t}$ & T10 - RB + MOS $1-0,5 \mathrm{~kg} / \mathrm{t}$ \\
T5 - RB + MOS $1-1,0 \mathrm{~kg} / \mathrm{t}$ & $\mathrm{T} 11-\mathrm{RB}+$ MOS $1-1,0 \mathrm{~kg} / \mathrm{t}$ \\
T6 - RB + MOS $2^{4}-1,0 \mathrm{~kg} / \mathrm{t}$ & $\mathrm{T} 12-\mathrm{RB}+$ MOS $2-1,0 \mathrm{~kg} / \mathrm{t}$ \\
\hline
\end{tabular}

${ }^{1}$ Avilamicina: $7 \mathrm{ppm}$ na fase inicial e $5 \mathrm{ppm}$ na fase de crescimento.

2 Simbiótico 1,0 kg/t composto pela associação de Bacillus subitilis + Bacillus licheniformis: $>3,2 \times 10^{9} / \mathrm{g}+$ MOS 1 .

3 MOS -1 Nutricell Mos 55 - fornecido pela Biorigim.

${ }^{4}$ MOS -2 BioMos- fornecido pela Alltech.

Tabela 2 - Composição nutricional dos grãos de milho

\begin{tabular}{lcc}
\hline Item & Milho normal & Milho de baixa qualidade \\
\hline Proteína (\%) & 7,80 & 9,56 \\
Umidade (\%) & 13,65 & 13,43 \\
Cinzas (\%) & 0,70 & 1,08 \\
Extrato etéreo (\%) & 3,43 & 2,91 \\
\hline
\end{tabular}

pelo de baixa qualidade, sem quaisquer correções, para obter os tratamentos com milho $\left(\mathrm{T}_{7}\right.$ a $\left.\mathrm{T}_{12}\right)$.

As temperaturas mínimas e máximas no interior da instalação foram de $23^{\circ} \mathrm{C}$ (máxima) e $15^{\circ} \mathrm{C}$ (mínima), para o período de 1 a 21 dias de idade, e de $24^{\circ} \mathrm{C}$ (máxima) e $16^{\circ} \mathrm{C}$ (mínima), para o período de 22 a 42 dias de idade.

Para aumentar o grau de desafio sanitário, as aves foram criadas sobre cama de maravalha reutilizada e os bebedouros não foram lavados periodicamente. Para calcular o fator de produção, utilizou-se a seguinte fórmula:

\section{GMD x VIAB}

$$
\mathrm{FP}=\frac{}{\mathrm{CA}} \times 100
$$

em que $\mathrm{FP}$ = fator de produção; $\mathrm{GMD}$ = ganho médio diário $(\mathrm{kg}) ;$ VIAB = viabilidade das aves $(\%) ; \mathrm{CA}$ = conversão alimentar.

Avaliaram-se o ganho de peso das aves, o consumo de ração, a conversão alimentar e a mortalidade, além do fator de produção obtido aos 42 dias de idade.

Tabela 3 - Composição em ingredientes e nutricional das dietas

\begin{tabular}{|c|c|c|}
\hline \multirow[b]{2}{*}{ Item } & \multicolumn{2}{|c|}{ Fase (dias) } \\
\hline & $1-21$ & $22-42$ \\
\hline \multicolumn{3}{|l|}{ Ingrediente (\%) } \\
\hline Milho & 55,88 & 62,24 \\
\hline Farelo de soja & 37,32 & 30,51 \\
\hline Óleo de soja & 2,62 & 3,34 \\
\hline Calcário & 0,98 & 0,93 \\
\hline Fosfato bicálcico & 1,81 & 1,61 \\
\hline L-lisina $\mathrm{HCl}$ 78,5\% & 0,11 & 0,19 \\
\hline DL-metionina 99\% & 0,21 & 0,20 \\
\hline Sal & 0,45 & 0,38 \\
\hline Mistura vitamínica ${ }^{1}$ & 0,10 & 0,10 \\
\hline Mistura mineral $^{2}$ & 0,05 & 0,05 \\
\hline Antioxidante ${ }^{3}$ & 0,01 & 0,01 \\
\hline Anticoccidiano $^{4}$ & 0,06 & 0,06 \\
\hline Cloreto de colina $60 \%$ & 0,10 & 0,08 \\
\hline Amido de milho & 0,30 & 0,30 \\
\hline \multicolumn{3}{|l|}{ Composição nutricional calculada } \\
\hline Energia metabolizável (kcal/ kg) & 2.975 & 3.100 \\
\hline Proteína bruta (\%) & 22,00 & 19,50 \\
\hline $\mathrm{Ca}(\%)$ & 0,961 & 0,872 \\
\hline P disponível (\%) & 0,450 & 0,410 \\
\hline $\mathrm{Na}(\%)$ & 0,220 & 0,193 \\
\hline Metionina digestível (\%) & 0,520 & 0,482 \\
\hline Metionina + cistina digestível (\%) & 0,810 & 0,741 \\
\hline Lisina digestível (\%) & 1,141 & 1,052 \\
\hline Treonina digestível (\%) & 0,740 & 0,652 \\
\hline Triptofano digestível (\%) & 0,250 & 0,209 \\
\hline Arginina digestível (\%) & 1,379 & 1,191 \\
\hline Glicina + serina $(\%)$ & 2,093 & 1,830 \\
\hline
\end{tabular}
basais (matéria natural) 
Para avaliar as mudanças nas características morfológicas aos 23 dias de idade, foram abatidas duas aves ao acaso por unidade experimental para retirada do fígado, da bursa de Fabricius, da perna (coxa e sobrecoxa) e do peito.

O fígado foi avaliado quanto à textura, coloração e presença ou não de hemorragias e lesões macroscópicas. Para o peito e a perna, foi avaliada a presença ou não de petéquias e para a bursa, o tamanho, utilizando-se bursímetro e o peso relativo.

Aos 42 dias, foram selecionadas e identificadas três aves por box, com peso médio da unidade experimental, e, posteriormente, abatidas para pesagem do fígado e avaliação do rendimento de carcaça, pernas (coxa e sobrecoxa), peito, filé de peito e gordura abdominal.

As carcaterísticas de desempenho e carcaça foram avaliadas utilizando-se o programa SAEG - Sistema para Análises Estatísticas e Genética (UFV, 2004) e, no caso de efeito significativo de tratamento, realizou-se a comparação de médias pelo teste Student Newman-Keuls (SNK), a 5\% de probabilidade.

\section{Resultados e Discussão}

Não houve interação $(\mathrm{P}>0,05)$ dos dois tipos de milhos e os aditivos utilizados nas rações experimentais sobre os parâmetros de desempenho avaliados aos 21 dias de idade (Tabela 4).

Verificou-se efeito não-significativo $(\mathrm{P}>0,05)$ da utilização de aditivos sobre o consumo de ração (Tabela 4). Resultados similares foram observados por Loddi (2002), Pelicano et al. (2004a) e Albino et al. (2006), ao utilizarem mananoligossacarídeos + ácidos orgânicos na ração de frangos de corte. Do mesmo modo, Toledo et al. (2003), trabalhando com dietas elaboradas com milho normal e milho de baixa qualidade, também não encontraram diferenças significativas $(\mathrm{P}>0,05)$ para o consumo de ração das aves.

As aves alimentadas com rações sem aditivos apresentaram ganho de peso inferior (Tabela 4) às aves dos tratamentos contendo diferentes aditivos $(\mathrm{P}<0,05)$, que não diferiram entre si $(\mathrm{P}>0,05)$. Os resultados sugerem que os aditivos utilizados foram eficientes para neutralizar ou reduzir os efeitos negativos decorrentes de contaminações do ambiente e das rações. Estes resultados são semelhantes aos verificados por Toledo et al. (2003) e Albino et al. (2006), que também relataram efeito benéfico para o ganho de peso das aves alimentadas com ração contendo prebióticos ou antibiótico, mas diferem dos obtidos por Loddi et al. (2002), que não notaram efeito para este parâmetro
Tabela 4 - Valores médios para consumo de ração (CR), ganho de peso (GP) e conversão alimentar (CA) de frangos de corte no período de 1 a 21 dias de idade

\begin{tabular}{lccc}
\hline & \multicolumn{3}{c}{ Desempenho } \\
\cline { 2 - 4 } Adição de aditivos & CR (g) & GP (g) & CA (g/g) \\
\hline Sem aditivo & 1.001 & $608 \mathrm{~B}$ & 1,656 \\
Antibiótico & 1.037 & $640 \mathrm{~A}$ & 1,632 \\
Simbiótico & 1.003 & $630 \mathrm{~A}$ & 1,604 \\
MOS $1-0,50 \mathrm{~kg} / \mathrm{t}$ & 1.030 & $641 \mathrm{~A}$ & 1,633 \\
MOS $1-1,0 \mathrm{~kg} / \mathrm{t}$ & 1.015 & $637 \mathrm{~A}$ & 1,602 \\
MOS $2-1,0 \mathrm{~kg} / \mathrm{t}$ & 1.009 & $630 \mathrm{~A}$ & 1,610 \\
\hline Qualidade do milho & & & \\
\hline Normal & $1.067 \mathrm{a}$ & $695 \mathrm{a}$ & $1,540 \mathrm{~b}$ \\
Baixa & $965 \mathrm{~b}$ & $566 \mathrm{~b}$ & $1,706 \mathrm{a}$ \\
\hline CV (\%) & 3,86 & 3,72 & 3,54 \\
\hline
\end{tabular}

Médias seguidas de letras diferentes maiúscula ou minúscula nas colunas diferem $(P<0,05)$ pelo teste SNK.

ao utilizarem probióticos, MOS + ácidos orgânicos em rações para frangos de corte.

Diferença significativa $(\mathrm{P}>0,05)$ não foi registrada para conversão alimentar entre os tratamentos (Tabela 4), resultados similares foram verificados por Albino et al. (2006), mas divergem dos encontrados por Toledo et al. (2003) e Pelicano et al. (2004a), que observaram efeitos dos prebióticos e probióticos nas rações sobre a conversão alimentar das aves.

A baixa qualidade do milho proporcionou efeito negativo no desempenho das aves aos 21 dias, com redução de $18,6 \%$ no ganho de peso e piora de $9,73 \%$ na conversão alimentar. Estes resultados também foram verificados por Toledo et al. (2003) e Rostagno et al. (2003), que relataram efeitos negativos para estas características, ao fornecerem rações com milho de baixa qualidade para frangos de corte, o que era esperado, visto que a presença de aflatoxinas afeta o metabolismo e, conseqüentemente, o desempenho das aves. Conforme Tessari et al. (2005), 50 ppb de aflatoxinas são suficientes para reduzir a resposta imunológica humoral à vacina contra a doença de New Castle. Esta redução facilita a ação dos microrganismos patogênicos e interfere nos resultados de desempenho.

$\mathrm{Na}$ avaliação das partes e dos órgãos das aves aos 23 dias de idade, não se observou efeito significativo $(\mathrm{P}>0,05)$ (Tabela 5). Estes resultados corroboram aqueles encontrados por Stringhini et al. (2000), ao utilizarem rações contendo 74,6 ppb de aflatoxinas. A não-observância dessas alterações resulta do baixo nível de aflatoxinas nas rações.

As características do fígado (coloração, textura e presença de hemorragias e lesões) e a presença de petéquias no peito e na perna (Tabela 5) não sofreram efeitos significativos 
Tabela 5 - Presença de petéquias no peito (PP) e na perna (PPN), lesões no fígado (LF), alterações na cor (CF), presença de hemorragia (HF) e alterações na textura do fígado (TF) de frangos de corte aos 23 dias de idade

\begin{tabular}{lcccccc}
\hline Adição de aditivos & \multicolumn{7}{c}{ Variável } \\
\cline { 2 - 7 } & P P & P P N & LF & CF & HF & TF \\
\hline Sem aditivo & 0,50 & 1,38 & 0,12 & 0,19 & 0,25 & 0,00 \\
Antibiótico & 0,50 & 1,69 & 0,37 & 0,69 & 0,31 & 0,00 \\
Simbiótico & 0,44 & 1,69 & 0,38 & 0,63 & 0,31 & 0,06 \\
MOS 1 - 0,50 kg/t & 0,81 & 1,37 & 0,19 & 0,31 & 0,25 & 0,00 \\
MOS 1 - 1,0 kg /t & 0,38 & 1,50 & 0,25 & 0,38 & 0,13 & 0,06 \\
MOS 2 - 1,0 kg/t & 0,56 & 1,44 & 0,12 & 0,25 & 0,19 & 0,00 \\
\hline Qualidade do milho & & & & & & \\
\hline Normal & 0,50 & 1,35 & 0,31 & 0,42 & 0,19 & 0,02 \\
Baixa & 0,56 & 1,60 & 0,17 & 0,40 & 0,29 & 0,02 \\
CV (\%) & 117,4 & 46,8 & 183,6 & 140,7 & 195,4 & 679,9 \\
\hline
\end{tabular}

Efeito não-significativo $(P>0,05)$.

( $\mathrm{P}>0,05)$, o que pode ser atribuído ao nível de aflatoxinas presente no milho.

Quanto ao peso relativo da bursa (Tabela 6), houve interação $(\mathrm{P}<0,05)$ dos tratamentos e tipos de milho, de modo que as aves que receberam ração com milho normal e simbiótico apresentaram menor peso da bursa. Para aquelas que receberam ração contendo MOS 1 (0,50 kg/t), o menor peso relativo da bursa foi encontrado nas aves alimentadas com milho de baixa qualidade. Para os demais tratamentos, não foi observada diferença entre os tipos de milho.

Não houve interação $(\mathrm{P}>0,05)$ dos aditivos e tipo de milho para os parâmetros de desempenho no período de 1 a 42 dias de idade (Tabela 7).

Houve melhora $(\mathrm{P}<0,05)$ de até $3,3 \%$ para o ganho de peso com o uso de aditivos. Resultados similares foram obtidos por Rostagno et al. (2003), Loddi et al. (2005) e Albino et al (2006).

Para a conversão alimentar, não foi encontrada diferença $(\mathrm{P}>0,05)$ entre os tratamentos (Tabela 7$)$, resultado similar ao obtido por Ferreira (2001) e Albino et al. (2006) e diferente dos descritos por Rostagno et al. (2003) e Santos et al. (2005), que atribuíram esta melhora ao poder de adsorção das bactérias patogênicas pelo MOS.

$\mathrm{O}$ fator de produção não foi influenciado $(\mathrm{P}>0,05)$ pelos aditivos utilizados, o que se assemelha aos resultados encontrados por Albino et al (2006), que também não encontraram diferença significativa ao utilizarem MOS na alimentação das aves. Embora não tenha ocorrido diferença significativa para o fator de produção, houve redução média de $45 \%$ com o uso de milho de baixa qualidade e aumento de $6 \%$ com a utilização do MOS.

A qualidade do milho afetou negativamente $(\mathrm{P}<0,05)$ os parâmetros de ganho de peso, consumo de ração e conver-
Tabela 6 - Peso da bursa em relação ao peso corporal aos 23 dias de idade

\begin{tabular}{lcc}
\hline Adição de aditivos & Milho normal & Milho baixa qualidade \\
\hline Sem aditivo & $0,29 \mathrm{Aa}$ & $0,26 \mathrm{Ba}$ \\
Antibiótico & $0,31 \mathrm{Aa}$ & $0,28 \mathrm{ABa}$ \\
Simbiótico & $0,27 \mathrm{Ab}$ & $0,34 \mathrm{ABa}$ \\
MOS $1-0,50 \mathrm{~kg} / \mathrm{t}$ & $0,32 \mathrm{Aa}$ & $0,27 \mathrm{ABb}$ \\
MOS $1-1,0 \mathrm{~kg} / \mathrm{t}$ & $0,27 \mathrm{Aa}$ & $0,30 \mathrm{ABa}$ \\
MOS $2-1,0 \mathrm{~kg} / \mathrm{t}$ & $0,27 \mathrm{Aa}$ & $0,30 \mathrm{ABa}$ \\
\hline Média de milho & 0,289 & 0,289 \\
\hline CV \% & 17,23 & \\
\hline
\end{tabular}

Médias seguidas de letras diferentes maiúsculas nas colunas ou minúsculas nas linhas diferem $(P<0,05)$ pelo teste SNK.

Tabela 7 - Consumo de ração (CR), ganho de peso (GP), conversão alimentar (CA) e fator de produção (F. Prod.) de frango de corte no período de 1 a 42 dias de idade

\begin{tabular}{llccc}
\hline Adição de aditivos & \multicolumn{4}{c}{ Desempenho } \\
\cline { 2 - 5 } & CR (g) & GP (g) & CA (g/g) & F. Prod. \\
\hline Sem aditivo & $4.315 \mathrm{~B}$ & $2.250 \mathrm{~B}$ & 1,927 & 267 \\
Antibiótico & $4.463 \mathrm{~A}$ & $2.391 \mathrm{~A}$ & 1,882 & 292 \\
Simbiótico & $4.369 \mathrm{AB}$ & $2.325 \mathrm{~A}$ & 1,886 & 273 \\
MOS 1 - 0,50 kg/t & $4.471 \mathrm{~A}$ & $2.335 \mathrm{~A}$ & 1,931 & 283 \\
MOS 1 - 1,0 kg/t & $4.412 \mathrm{AB}$ & $2.356 \mathrm{~A}$ & 1,882 & 282 \\
MOS 2 - 1,0 kg/t & $4.368 \mathrm{AB}$ & $2.332 \mathrm{~A}$ & 1,879 & 273 \\
\hline Qualidade do milho & & & & \\
\hline Normal & $4.614 \mathrm{a}$ & $2.557 \mathrm{a}$ & $1,806 \mathrm{~b}$ & $330 \mathrm{a}$ \\
Baixa & $4.186 \mathrm{~b}$ & $2.105 \mathrm{~b}$ & $1,990 \mathrm{a}$ & $227 \mathrm{~b}$ \\
\hline CV (\%) & 3,13 & 3,78 & 3,05 & 8,7
\end{tabular}

Médias seguidas de letras diferentes maiúsculas nas colunas ou minúsculas nas linhas diferem $(\mathrm{P}<0,05)$ pelo teste SNK.

são alimentar (Tabela 7). Estes resultados corroboram os encontrados em estudo com milho em diferentes níveis de carunchamento (Stringhini et al., 2000; Rostagno et al., 2003; Toledo et al., 2003), com milho de baixa qualidade e milho carunchado e contaminado com vários níveis de aflatoxinas (Souza, 2003). No entanto, discordam daqueles encontrados por Ott et al. (2004), que utilizaram milho mofado contendo $33 \mathrm{ppb}$ de aflatoxina e observaram efeitos significativos somente quando adicionados $3 \mathrm{ppm}$ de aflatoxinas. A piora na conversão alimentar pode ser explicada pela redução no valor de energia disponível decorrente da baixa qualidade do milho (Krabbe, 1995; Silva et al., 2005). Observou-se ainda redução de $17,70 \%$ no ganho de peso das aves e piora de $9,90 \%$ na conversão alimentar com a utilização do milho de baixa qualidade.

A mortalidade e o peso relativo do fígado das aves (Tabela 8) não foram influenciados $(\mathrm{P}>0,05)$ pelos aditivos não-nutrientes utilizados na ração, o que confirma os dados obtidos por Albino et al (2006), que também não verificaram 
Tabela 8 - Percentual de mortalidade das aves nos períodos de 1 a 21 dias, 22 a 42 dias e 1 a 42 dias de idade e peso relativo do fígado aos 42 dias de idade

\begin{tabular}{|c|c|c|c|c|}
\hline \multirow[t]{3}{*}{ Adição de aditivos } & \multicolumn{4}{|c|}{ Variável } \\
\hline & \multicolumn{3}{|c|}{$\%$ mortalidade } & \multirow[t]{2}{*}{ Fígado (\%) } \\
\hline & 1 a 21 & 22 a 42 & 1 a 42 & \\
\hline Sem aditivo & 0,85 & 4,38 & 6,81 & 3,32 \\
\hline Antibiótico & 0,85 & 3,44 & 3,97 & 3,31 \\
\hline Simbiótico & 2,84 & 5,62 & 7,95 & 3,42 \\
\hline MOS $1-0,50 \mathrm{~kg} / \mathrm{t}$ & 2,55 & 2,50 & 4,54 & 3,31 \\
\hline MOS $1-1,0 \mathrm{~kg} / \mathrm{t}$ & 2,55 & 5,56 & 7,67 & 3,31 \\
\hline MOS $2-1,0 \mathrm{~kg} / \mathrm{t}$ & 2,27 & 5,00 & 6,81 & 3,32 \\
\hline \multicolumn{5}{|l|}{ Qualidade do milho } \\
\hline Normal & 1,510 & $1,560 \mathrm{~b}$ & $3,030 b$ & $3,10 \mathrm{~b}$ \\
\hline Baixa & 2,436 & 7,290a & $9,560 \mathrm{a}$ & 3,59a \\
\hline CV (\%) & 148,4 & 124,5 & 96,7 & 6,00 \\
\hline
\end{tabular}

Médias seguidas de letra diferente minúscula na coluna diferem $(P<0,05)$ pelo teste SNK.

diferenças significativas na viabilidade das aves, ao utilizarem MOS na alimentação de frangos de corte.

Verificaram-se, no entanto, menores mortalidade e peso de fígado para as aves que receberam ração formulada com milho normal (melhor qualidade). Ocorreram aumentos de $6 \%$ na mortalidade e de $13,50 \%$ no peso relativo do fígado das aves que receberam dieta formulada com o milho de baixa qualidade, provavelmente devido à presença das aflatoxinas.

Ressalta-se, portanto, a importância de se formularem rações para frangos de corte com milho de melhor qualidade para obtenção de maior índice de produção e, conseqüentemente, maior lucratividade na criação das aves.

Os resultados de peso relativo do fígado assemelham-se aos verificados por Souza (2003), que encontrou aumento linear neste parâmetro com o incremento dos níveis de aflatoxinas no milho, e discordam daqueles verificados por Stringhini et al. (2000), que não encontraram efeito para a mesma variável aos 49 dias de idade das aves, ao utilizarem milhos contendo diferentes níveis de infestação por insetos ou fungos na elaboração das rações experimentais. Todavia, segundo Ott et al. (2004), o aumento do peso do fígado ocorre somente em aves alimentadas com dietas contendo níveis acima de 3 ppm de aflatoxinas.

Observou-se efeito não-significativo $(\mathrm{P}>0,05)$ para rendimentos de carcaça, perna, peito, filé de peito e gordura abdominal (Tabela 9). Estes resultados também foram evidenciados por Vargas Jr. et al. (2002) e Pelicano et al. (2004b), que também não encontraram efeito de prebióticos e probióticos sobre essas características, mas são contrários àqueles verificados por Albino et al (2006), que observaram melhora nos rendimentos de peito, filé de peito e perna e na
Tabela 9 - Rendimentos de carcaça (RC), peito (RP), perna (RPN), gordura abdominal (GAB) e filé de peito (RFP) de frangos de corte

\begin{tabular}{lccccc}
\hline Adição de aditivos & \multicolumn{5}{c}{ Variável } \\
\cline { 2 - 6 } & RC\% & RP\% & RPN\% & GAB\% & RFP \% \\
\hline Sem aditivo & 68,92 & 35,35 & 30,19 & 1,84 & 26,78 \\
Antibiótico & 69,31 & 34,23 & 30,30 & 1,68 & 26,24 \\
Simbiótico & 68,87 & 35,15 & 30,31 & 1,52 & 26,74 \\
MOS 1 - 0,50 kg/t & 68,83 & 34,88 & 30,40 & 1,62 & 26,71 \\
MOS 1 - 1,0 kg/t & 69,00 & 35,24 & 30,75 & 1,67 & 26,73 \\
MOS 2 - 1,0 kg/t & 69,56 & 35,38 & 29,97 & 1,59 & 26,89 \\
\hline Qualidade do milho & & & & & \\
\hline Normal & $70,23 a$ & 35,12 & $29,66 b$ & $1,61 a$ & 26,70 \\
Baixa & $67,94 b$ & 34,97 & $30,97 a$ & $1,25 b$ & 26,73 \\
\hline CV (\%) & 2,3 & 3,4 & 3,2 & 20,6 & 3,9 \\
\hline
\end{tabular}

Médias seguidas de letra diferente minúscula na coluna diferem $(P<0,05)$ pelo teste SNK.

deposição de gordura abdominal. Diferem também dos descritos por Santos et al. (2005), que observaram maior rendimento de carcaça quando utilizaram ácido fumárico e maior rendimento de peito quando utilizaram antibiótico e MOS na dieta de frangos de corte.

O milho de baixa qualidade influenciou $(\mathrm{P}<0,05)$ negativamente o rendimento de carcaça e reduziu a deposição de gordura abdominal, mas proporcionou melhor rendimento de perna, não afetando os rendimentos de peito e filé de peito, o que concorda, em parte, com os dados registrados por Souza (2003), que não verificou diferenças nos rendimentos de coxa, sobrecoxa, peito e carcaça e no rendimento de dorso, quando utilizou milho com diferentes níveis de carunchamento em rações para frangos de corte.

\section{Conclusões}

Os prebióticos à base de mananoligossacarídeos e o simbiótico podem substituir o antibiótico avilamicina nas rações para aves. $\mathrm{O}$ uso de milho de baixa qualidade piora o desempenho zootécnico e prejudica o rendimento e a qualidade de carcaça de frangos de corte.

\section{Literatura Citada}

ALBINO, L.F.T.; FERES, F.A.; DIONIZIO, M.A. et al. Uso de prebiótico à base de mananoligossacarideo em rações para frangos de corte. Revista Brasileira de Zootecnia, v.35, n.3, p.742749, 2006.

ARAÚJO, L.F.; JUNQUEIRA, O.M.; ARAÚJO, C.S.S. et al. Antibiótico e prebiótico para frangos de corte no período de 24 a 41 dias de idade. In: REUNIÃO ANUAL DA SOCIEDADE BRASILEIRA DE ZOOTECNIA, 37., 2000, Viçosa, MG. Anais... Viçosa, MG: Sociedade Brasileira de Zootecnia, 2000. (CD-ROM) 
FERREIRA, F.A.B. [2001]. Uso de antibioticos ácidos organicos e prebioticos na alimentação de frangos de corte. Disponível em: <www.capes.gov.br/ag.DW/fr.pesquisa.teses.> Acesso em: $10 / 12 / 2004$.

KRABBE, E.L.; JUNCHEM, S.; MACIEL, J.E.S. et al. Efeito das condições de armazenagem de grãos de milho na energia metabolizável aparente para frangos de corte criados com rações de diferentes qualidades. In: CONFERENCIA APINCO 95 DE CIÊNCIA E TECNOLOGIA AVÍCOLA, Curitiba, 1995. Trabalhos de Pesquisa... Curitiba: Fundação APINCO de Ciência e Tecnologia Avícolas, 1995. p.9.

LODDI, M.M.; TUCCI, F.M.; HANNAS; M.I. et al. Probióticos, Mananoligossacarídeos + ácidos orgânicos em dietas para frangos. In: REUNIÃO ANUAL DA SOCIEDADE BRASILEIRA DE ZOOTECNIA, 39., 2002, Recife. Anais... Recife: Sociedade Brasileira de Zootecnia 2002. (CD-ROM).

LODDI, M.M.; CARVALHO, T.B.; WITSMISZYN et al. Mananoligossacarídeo, ácidos orgânicos e antibiótico: respostas em aves desafiadas com Salmonella. Revista Brasileira de Ciência Avícola, v.7, p.67, 2005.

LUQUETTI, B.C.; FARIA FILHO, D.E.; FIGUEIREDO, D. et al. Uso de prebiótico reduz o escore de lesão no intestino delgado de frangos vacinados contra coccidiose. Revista Brasileira de Ciências Avícola, v.7, p.203, 2005.

MINISTÉRIO DA AGRICULTURA E ABASTECIMENTO - MAPA. Compêndio brasileiro de alimentação animal. Brasília: 1998. p.20.

OTT, R.P.; VIEIRA, S.L.; SANTURIO, J.M. et al. Desempenho de frangos de corte consumindo dietas com diferentes níveis de contaminação fúngica e suplementados com MYCOSORB. Revista Brasileira de Ciência Avícola, v.6, p.64, 2004.

PELICANO, E.R.L.; SOUZA, P.A.; SOUZA, H.B.A. et al. Utilização de probióticos e/ou prebióticos como promotores de crescimento em rações iniciais de frangos de corte. Revista Brasileira de Ciência Avícola, v.6, p.17, 2004a.

PELICANO, E.R.L.; SOUZA, P.A.; SOUZA, H.B.A. et al. Efeito do uso de probióticos e/ou prebióticos sobre rendimentos de carcaça de frangos de corte. Revista Brasileira de Ciência Avícola, v.6, p.18, 2004b.

PELICANO, E.R.L.; SOUZA, P.A.; SOUZA, H.B.A. et al. Microscopia eletrônica de varredura da mucosa intestinal de frangos de 21 dias de idade produzidos com probióticos e prebióticos. Revista Brasileira de Ciência Avícola, v.7, p.63, 2005.

PELICIA, K.; MENDES, A.A.; SALDANHA, E.S.P.B. et al. Utilização de promotores biológicos para frangos de corte tipo colonial. Revista Brasileira de Ciência Avícola, v.6, p.21, 2004.

ROSTAGNO, H.S.; ALBINO, L.F.T.; DONZELE, J.L. et al. Tabelas brasileiras para aves e suínos. Composição de alimentos e exigências nutricionais. Viçosa, MG: Universidade Federal de Viçosa, 2000. 141p.

ROSTAGNO, H.S.; ALBINO, L.F.T.; TOLEDO, R.S. et al. Avaliação de prebioticos à base de manonoligossacarídeos em rações de frangos de corte contendo milhos de diferente qualidade nutricional. Revista Brasileira de Ciência Avícola, v.5, p.52, 2003.

SANTOS, E.C.; TEIXEIRA, A.S.; FREITAS, R.T.F. et al. Uso de aditivos promotores de crescimento sobre o desempenho, característica de carcaça e bactérias total do intestino de frango de corte. Ciência Agrotécnica, v.29, n.1, p.223-231, 2005.

SILVA, C.R.; ALBINO, L.F.T.; ROSTAGNO, H.S. et al. Valores energéticos de alguns alimentos usados na alimentação de frangos de corte. Revista Brasileira de Ciência Avícola, Suplemento 7, p.75, 2005.

SILVA, E.N. [2004]. A polêmica da resistência a antibióticos em aves. Disponível em: <www.abrappa.org.br/Apresentação ppt.> Acesso em: 30/0/2005.

SOUZA, A.V.C. Valor nutricional de grãos atacados por insetos ou contaminados por micotoxinas para frango de corte. Viçosa, MG: Universidade Federal de Viçosa, 2003. 160p. Tese (Doutorado em Zootecnia) - Universidade Federal de Viçosa, 2003.

STRINGHINI, J.H.; MOGYCA, N.S.; ANDRADE, M.A. et al. Efeito da qualidade do milho no desempenho de frangos de corte. Revista Brasileira de Zootecnia, v.29, n.1, p.191-198, 2000.

TARDIN, A.C. Produção de rações na granja: Programa mínimo de qualidade. In: SIMPÓSIO TÉCNICO DE PRODUÇÃO DE OVOS, 1., 1991, Campinas. Anais... São Paulo: Associação Paulista de Avicultura, 1991. p.50-72.

TESSARI, E.N.C.; OLIVEIRA, C.A.F.; CARDOSO, A.L.S.P. Efeitos da aflatoxina $B_{1}$ sobre a resposta imunológica humoral em frangos de corte vacinados contra doença de Newcastle. Revista Brasileira de Ciências Avícola, Suplemento 7, p.198, 2005

TOLEDO, R.S.; ROSTAGNO, H.S.; ALBINO, L.F.T. et al. Efeito de prebióticos e milho de diferentes qualidades nutricional sobre o desempenho de frangos de corte na fase inicial. In: REUNIÃO ANUAL DA SOCIEDADE BRASILEIRA DE ZOOTECNIA, 2003, Santa Maria. Anais.... Santa Maria: Sociedade Brasileira de Zootecnia, 2003. (CD-ROM).

UNIVERSIDADE FEDERAL DE VIÇOSA - UFV. SAEG - Sistema de Análises Estatísticas e Genéticas. Versão 8.0. Viçosa, MG: 2004. 59p (Manual do usuário)

VARGAS JR., J.G.; TOLEDO, R.S.; ALBINO, L.F.T. et al. Características de carcaça de frangos de corte submetidos a rações contendo probiótico, prebiótico e antibióticos. In: REUNIÃO DA SOCIEDADE BRASILEIRA DE ZOOTECNIA, 39., 2002, Recife Anais.... Recife: Sociedade Brasileira de Zootecnia, 2002. (CD-ROM). 